\title{
OPINION
}

\section{From hepatitis to hepatocellular carcinoma: a proposed model for cross-talk between inflammation and epigenetic mechanisms}

Marion Martin and Zdenko Herceg*

\begin{abstract}
Inflammation represents the body's natural response to tissue damage; however, chronic inflammation may activate cell proliferation and induce deregulation of cell death in affected tissues. Chronic inflammation is an important factor in the development of hepatocellular carcinoma (HCC), although the precise underlying mechanism remains unknown. Epigenetic events, which are considered key mechanisms in the regulation of gene activity states, are also commonly deregulated in HCC. Here, we review the evidence that chronic inflammation might deregulate epigenetic processes, thus promoting oncogenic transformation, and we propose a working hypothesis that epigenetic deregulation is an underlying mechanism by which inflammation might promote HCC development. In this scenario, different components of the inflammatory response might directly and indirectly induce changes in epigenetic machineries ('epigenetic switch'), including those involved in setting and propagating normal patterns of DNA methylation, histone modifications and non-coding RNAs in hepatocytes. We discuss the possibility that selfreinforcing cross-talk between inflammation and epigenetic mechanisms might amplify inflammatory signals and maintain a chronic state of inflammation culminating in cancer development. The potential role of inflammation-epigenome interactions in the emergence and maintenance of cancer stem cells is also discussed.
\end{abstract}

Keywords Cancer stem cells, epigenetic mechanisms, epigenetic switch, hepatitis, hepatocellular carcinoma, inflammation.

*Correspondence: herceg@iarc.fr

Epigenetics Group, International Agency for Research on Cancer (IARC), 150 Cours Albert Thomas, 69372 Lyon CEDEX 08, France

\section{Hepatocellular carcinoma: the importance of inflammation and epigenetics}

Hepatocellular carcinoma (HCC) is the major form of primary liver cancer in the world [1], accounting for 662,000 deaths worldwide per year [2]. HCC is frequently diagnosed at an advanced stage, resulting in rather poor survival rates. HCC typically starts with a pre-existing liver disease caused by infection with hepatitis $\mathrm{B}$ virus (HBV) or hepatitis C virus (HCV), chronic aflatoxin exposure or alcohol consumption [3]. Chronic liver damage associated with chronic exposure to these agents results in cirrhosis (scarring of the liver characterized by the formation of fibrous tissue and destruction of normal architecture of the organ), which can eventually progress to liver cancer. People infected with HCV have an $80 \%$ chance of developing cirrhosis, and HBV-infected people have a 30 -fold higher risk of developing cancer [1,3]. Therefore, there is a need for better understanding of the mechanisms underlying HCC development and progression, as these might improve our ability to detect the disease at earlier stages and design new efficient strategies for detection and treatment.

Deregulation of the epigenome (the totality of epigenetic marks in a cell, including DNA methylation, histone modifications and non-coding RNAs) is thought to play an important role in tumor development and progression. Epigenetic events are considered key mechanisms in the regulation of gene activity, and abnormal expression of a large number of tumor-suppressor genes and cancer-associated genes has been observed in a wide range of human cancers [4-8]. Epigenetic alterations might occur as early events in carcinogenesis and might precede genetic alterations during oncogenic transformation [9]. Moreover, large-scale studies involving epigenomic technologies have identified new genes targeted by aberrant epigenetic changes, and indicated epigenetic patterns that are consistently associated with different cancer types, including lung cancer, colorectal cancer and HCC. These 'epigenetic signatures' can be associated with predisposition factors or clinical outcome $[4,10,11]$, and can be defined as specific epigenetic changes or a 
combination thereof that are consistently associated with etiological or clinicopathological features of a tumor.

The inflammatory response is the tissue's natural response to damage. The primary functions of the inflammatory process are to defend the organism against harmful agents and products, remove damaged cells and facilitate the renewal of damaged tissues. However, chronic inflammation might activate cell proliferation and deregulation of cell death in affected tissues $[12,13]$. Inflammation is an important factor in HCC development, and chronic hepatitis might promote hepatocarcinogenesis through induction of cirrhosis, although inflammation-mediated HCC tumors might also develop in the absence of cirrhotic lesions. Because deregulation of epigenetic mechanisms is one of the hallmarks of cancer, including $\mathrm{HCC}$, it is possible that inflammation might act through epigenetic mechanisms to promote liver cancer. Several comprehensive reviews on the role of either epigenetic deregulation [11] or inflammation [14] individually in liver cancer have been published. Here, we focus on the potential role of epigenetic mechanisms in inflammation-mediated processes during hepatocarcinogenesis and discuss how a cross-talk between inflammation and the epigenome can be exploited in the development of novel and efficient strategies for the treatment and prevention of liver cancer.

\section{Deregulation of the inflammatory response during hepatocarcinogenesis}

HCC is one of the well-known examples of inflammationrelated cancer that slowly develops on a background of chronic inflammation. The molecular links that connect inflammation and liver tumors are not fully known; however, recent studies are beginning to unravel the underlying mechanisms. In this section, we will discuss the development of chronic inflammation in response to liver damage and viral infection, and then describe the role of cytokine secretion during HCC development. Finally, activation of nuclear factor (NF)- $\kappa$ B and STAT3 (signal transducers and activators of transcription 3) pathways and their consequences for hepatocarcinogenesis will be discussed.

\section{Development of chronic inflammation in response to liver damage and viral infection}

One of the main functions of the liver is to detoxify the organism. Consequently, hepatocytes are constantly subjected to diverse infectious or toxic agents that can generate liver damage and initiate an inflammatory response [15]. The purpose of local inflammation is to clear the damage by activating apoptosis of affected hepatocytes, and to promote repair of the tissue by activating cell proliferation [12]. Under normal conditions, when damage is limited and can be rapidly repaired, the inflammatory state is transient. However, if the tissue damage is severe or if the inflammatory stimulus persists, the inflammatory process is maintained and may progress to chronic inflammation with continuous proliferation of hepatocytes (see below). The cellular pathways that are activated during a prolonged inflammatory response may trigger a wide range of potentially harmful processes, such as induction of DNA damage through reactive oxygen species (ROS) accumulation [16]. Therefore, hepatocytes harboring extensive DNA damage and undergoing prolonged proliferation during chronic inflammation may result in the acquisition of mutations and growth advantages, thus promoting initiation and progression of hepatocellular carcinoma [17].

This scenario is more likely to be associated with excessive alcohol consumption or fat accumulation, or occur during infection with $\mathrm{HBV}$ or $\mathrm{HCV}$. HBV or HCV infection can lead to cirrhosis and further development of HCC when the immune system fails to efficiently clear the virus from the liver, resulting in a chronic form of the disease [18-20]. During an infection, hepatitis virus antigens activate immune cells that trigger apoptosis of infected hepatocytes, thus inducing compensatory proliferation [21]. Chronic infection may also lead to the development of HCC through induction of mutations and chromosomal instability [22]. These genetic changes can occur during prolonged cell proliferation and, in the case of HBV infection, can be induced by integration of the viral DNA into human chromosomal DNA $[18,20,23,24]$. HBV and HCV can also directly initiate cell transformation through the actions of viral proteins that interfere with cellular pathways controlling cell survival, cell proliferation and apoptosis [25]. For example, the HBV protein encoded by the $H B X$ gene is able to directly influence the transcription of genes involved in several signaling pathways, including c-JUN, c- $F O S$, c- $M Y C, A P-1$ and P53 $[19,26]$. In HCV, the core protein (the viral gene product synthesized in the early phase of HCV infection) is known, among others, to inhibit apoptosis through activation of c-MYC and inhibition of the P53 gene $[27,28]$. Therefore, chronic inflammation in the liver associated with viral infection may contribute to hepatocarcinogenesis through the deregulation of important cellular pathways.

\section{Cytokine secretion and HCC development}

During chronic inflammation of the liver, hepatocyte proliferation is activated by local and infiltrated immune cells through paracrine signals involving cytokines $[29,30]$ (Table 1). Among a wide range of cytokines involved in liver inflammation, TNF $\alpha$, interleukins (IL6, IL1 $\alpha$, IL1 $\beta \alpha$ and IL10), and TGF $\beta$ (transforming growth factor beta) are thought to play major roles [31]. Several large-scale studies investigating serum levels of cytokines revealed 
Table 1. Detected changes in selected cytokines in hepatocellular carcinoma and liver inflammation

\begin{tabular}{lllr}
\hline Cytokine & Upregulated or downregulated & Sample/material studied & \multicolumn{1}{c}{ References } \\
\hline TNFa & Up and down & Cirrhotic tissue, HCC patient serum, solid tumors & {$[31,33,38,41,42]$} \\
IL6 & Up and down & Cirrhotic tissue, hepatitis C, HCC patient serum & {$[31-34,40,41,43,137]$} \\
IL1a & Up & HCC patient serum & {$[31,33]$} \\
IL1 $\beta$ & Up & Cirrhotic tissue, HCC patient serum, solid tumors & {$[31,33,38,42]$} \\
TGF $\beta$ & Up and down & Urine, HCC patient serum & {$[31,36]$} \\
IL10 & Up & Cirrhotic tissue, hepatitis B, HCC patient serum & {$[31,32,35,37,39,60]$} \\
\hline
\end{tabular}

HCC, hepatocellular carcinoma; IL, interleukin; TGF, transforming growth factor; TNF, tumor necrosis factor.

higher levels of IL1 $\beta$, IL6, TNF $\alpha$, TGF $\beta$ and IL10 in individuals with hepatitis in comparison with healthy controls [32-40]. Curiously, serum levels of IL6 and TNF $\alpha$ have been found to be lower in patients with HCC [41], whereas in solid tumors TNF $\alpha$ and IL1 $\beta$ levels are higher in normal tissue than in tumor cells [42]. These studies have provided inconsistent results; therefore, the precise impact of cytokine deregulation associated with chronic inflammation in liver cancer development remains unclear. Nevertheless, changes in cytokine expression are detectable in pre-cancerous stages such as chronic hepatitis and cirrhosis. Comparison between different forms of liver inflammation has revealed higher levels of IL6, TNF $\alpha$, IL1 $\beta$ and IL10 in patients that have developed cirrhosis compared with those infected with HBV or $\mathrm{HCV}$ in the absence of cirrhosis $[37,38,43]$. Hence, cytokine expression is positively correlated with disease progression, suggesting that the deregulation of cytokine expression may be an early event in hepatocarcinogenesis that could actively participate in cancer development.

\section{NF-KB and STAT3 pathway activation and their} consequences for hepatocarcinogenesis

Cellular pathways activated by cytokines are involved in cell growth, cell survival, cell proliferation and apoptosis. Here we discuss the importance of the NF- $\mathrm{KB}$ and janus kinase (JAK)/STAT3 pathways in key biological functions that are deregulated in $\mathrm{HCC}[15,44,45]$.

NF- $\kappa \mathrm{B}$ belongs to the REL transcription factor family and exists as a homodimer or heterodimer. In the absence of stimuli, the dimers remain inactive in the cytoplasm [46]. In liver cells, binding of TNF $\alpha$ or IL1 $\alpha$ to the cellular membrane leads to the activation of NF- $\mathrm{kB}$, which can enter the nucleus and initiate transcription of several inflammatory target genes [46]. Even though NF-kB activation has been demonstrated in several solid tumors [47], few studies have investigated NF-kB status in HCC. In a small study involving 15 primary tumors, activation of $\mathrm{NF}-\mathrm{\kappa B}$ was detected in $87 \%$ of peritumoral tissues and in $80 \%$ of tumor tissues compared with healthy controls [48]. More recently, investigation of a larger cohort indicated activation of NF- $\mathrm{kB}$ in $25 \%$ of the tumor samples [49].
In contrast to studies using human cancer samples, there are many studies that have aimed to understand the role of NF- $\mathrm{KB}$ in hepatocarcinogenesis using in vivo rodent models of inflammation-induced HCC. These studies have revealed a dual function of NF-kB. First, as an anti-tumorigenic agent in hepatocytes, NF- $\mathrm{kB}$ may protect the liver by preventing excessive cell death and thus limiting the compensatory proliferation $[49,50]$. Second, there may be a pro-tumorigenic function whereby NF- $\mathrm{KB}$ activation may support tumor growth by increasing transformed hepatocyte proliferation [51,52]. Hence, the precise function of NF- $\mathrm{KB}$ activation during $\mathrm{HCC}$ initiation and development remains to be defined.

The JAK/STAT3 pathway may be activated through interaction of the cytokine IL6 with its receptor. IL6 binding activates the phosphorylation of a JAK (mostly JAK2), which in turn will phosphorylate STAT3 on amino acid Y705 [53]. Activated STAT3 forms homodimers and is translocated into the nucleus where it enhances the transcription of several genes belonging mainly to cell survival pathways. Other studies have observed that STAT3 is constitutively activated in a majority of HCC cases $(60 \%$ or more of the samples analyzed) [54,55]. Additionally, mechanistic studies in vivo revealed that STAT3 activation cannot be a consequence of HCC but may actively participate in the progression from hepatitis to an advanced cancer stage. In a mouse model of inflammation induced by specific dietary regimes, HCC incidence is correlated with STAT3 activation [56], and in mice developing a liver inflammatory microenvironment, HCC occurrence is reduced by STAT3 inhibition [49]. These results hint at a pro-tumorigenic role of the JAK/ STAT3 pathway in HCC growth, and also in HCC initiation and development.

\section{Deregulation of epigenetic mechanisms during hepatocarcinogenesis}

In cancer cells, the key cellular processes such as cell survival, cell growth, cell proliferation and apoptosis are deregulated by aberrant gene expression. Alterations in gene expression can be caused by epigenetic deregulation as well as genetic changes (that is, mutations) [7,57]. 
Epigenetic mechanisms, such as DNA methylation, histone modifications and non-coding RNAs are key regulators of gene activity states; therefore, epigenetic disruptions can affect transcription of the genes that establish and maintain cell identity and proliferation capacity. A number of studies have suggested that epigenetic mechanisms are altered in HCC and may play key roles in hepatocarcinogenesis [11] (Table 2).

\section{DNA methylation changes in HCC}

DNA methylation is a chemical modification of DNA, involving the addition of a methyl group $(-\mathrm{CH} 3)$ to a nucleotide. In humans, methylation usually occurs at the fifth carbon atom in the nucleotide base cytosine (5-methylcytosine). DNA methylation has been primarily studied in the context of gene transcription and aberrant gene silencing, although it has also been implicated in the silencing of transposable elements [58]. DNA methylation impacts the level of compaction of chromatin, and this affects the interaction between DNA and transcription factors, and consequently influences DNA expression. Global genome hypomethylation is a common phenomenon found in many solid tumors, including HCC [59]. The comparison of global methylation levels in HCC tumors and matched non-tumorigenic liver tissues revealed a significant reduction in total 5-methylcytosine content in tumors [60]. Compared with the surrounding cirrhotic or non-neoplastic tissues, lower levels of methylation at repetitive elements LINE-1,ALU and SAT-2 have been observed in liver tumors [61].

Global hypomethylation can contribute to carcinogenesis in two ways. First, in normal liver tissue, as in other healthy tissues, methylation of repetitive elements may contribute to genome integrity by silencing their transcription, thus preventing the activity of potentially harmful mobile genetic elements. DNA hypomethylation could thus explain the chromosome structural alterations and genetic mutations observed in HCC. This hypothesis is corroborated by a study showing that an excess of copies of the heterochromatin sequence 1q12 is correlated with global loss of methylcytosine [62]. Therefore, DNA hypomethylation may alter the interaction between the CpGrich satellite DNA and chromatin proteins, resulting in heterochromatin decondensation and breakage. Second, global hypomethylation can result in oncogene activation. This notion is supported by oncogene promoter demethylation found during HCC progression $[59,63]$.

In parallel to these genome-wide alterations, regional hypermethylation has been detected in CpG islands of tumor suppressor genes (TSGs) [59,63-65]. These hypermethylated CpG islands result most often in gene silencing. The targeted genes are involved in cell proliferation inhibition (p16INK4A, $p 21, p 27$, RASSF1A, SOCS1-3, RIZ1), apoptosis (CASP8, XAF-1, ASPP1, ASPP2), cell adhesion and migration (E-Cadherin, TFPI-2), and DNA repair (GSTP1), and their silencing can promote cell transformation. TSGs and other cancer-associated genes (such as RASSF1A, DOK1 and CHRNA3) have been found to be hypermethylated in a high percentage of human samples of HCC $[63,66]$. Importantly, precancerous lesions in liver, such as fibrosis and cirrhosis, have also been found to exhibit aberrant hypermethylation in TSGs [11]. These observations suggest that TSG hypermethylation may represent a tumor-initiating event in HCC progression. Together, changes in methylation states (both hypermethylation and hypomethylation) appear to play a critical role in liver tumor development, similar to other cancers such as colorectal cancer and BeckwithWiedermann syndrome [67].

\section{Histone modifications in hepatocellular carcinoma}

Chemical modifications on histones (mainly acetylation and methylation on histones $\mathrm{H} 3$ or $\mathrm{H} 4$ ) are involved in gene expression through their role in the recruitment of inhibitors or enhancers of transcription. These modifications occur essentially in gene promoters to stimulate or inhibit gene expression.

In a methyl-deficient rodent model of hepatocarcinogenesis, in which hepatocarcinogenesis can be followed from preneoplastic nodules [68], it has been found that levels of H3K9 and H4K20 trimethylation (histone marks associated with repressive and activating transcriptional states, respectively) change during cancer development. In accordance with these changes, upregulation and downregulation of Suv39h1 and Suv4-20h2, the enzymes responsible for H3K9 and H4K20 methylation, have been observed.

Progressive changes in histone mark patterns (mediated by activation or inactivation of specific histone-modifying complexes) have also been observed in a model of cell reprogramming. Fusion of mouse HCC cells with embryonic stem cells results in the loss of HCC cellular phenotype and reactivation of the tumor suppressor gene p16INK4A. Induced differentiation of these reprogrammed cells restores the original HCC phenotype in association with progressive silencing of $p 16 I N K 4 A$ [69]. During differentiation, the p16INK4A promoter is promptly 'invaded' by H3K27 trimethylation, accompanied by H3K9 dimethylation at later stages. Finally, histone $\mathrm{H} 3$ and $\mathrm{H} 4$ deacetylation (commonly associated with inhibition of transcription) are involved in several gene expression alterations in HCC [70,71], and mechanistic studies have revealed that histone deacetylation could also act in association with DNA methylation to induce gene silencing $[64,65]$. Despite the lack of largescale studies with human samples, these results suggest that histone modifications may play an important role in hepatocarcinogenesis. 
Table 2. Epigenetic deregulation in hepatocellular carcinoma

\begin{tabular}{|c|c|c|c|}
\hline & Upregulation or downregulation & Sample/material studied & Reference(s) \\
\hline \multicolumn{4}{|l|}{ DNA methylation } \\
\hline Genome-wide & Down & Tumors & {$[60,62]$} \\
\hline Repetitive elements (LINE-1, SAT-2, ALU) & Down & Tumors & [61] \\
\hline p16INK4A (TSG) & Up & Cirrhotic tissue, blood, serum, tumors & {$[59,63,86]$} \\
\hline RASSFIA (TSG) & Up & Cell lines, cirrhotic tissue, serum, tumors & {$[59,63,86]$} \\
\hline SOCS1 (TSG) & Up & Cell lines, tumors & {$[55,59,63,102]$} \\
\hline E-Cadherin (TSG) & Up & Cirrhotic tissue, tumors & {$[63,86]$} \\
\hline GSTP1 (TSG) & Up & Serum, tumors & {$[59,63,86]$} \\
\hline \multicolumn{4}{|l|}{ Histone mark } \\
\hline H3K9 dimethylation & Up & Cell lines & [69] \\
\hline $\mathrm{H} 3 \mathrm{~K} 9$ trimethylation & Up & Rodent models & [68] \\
\hline H3K27 trimethylation & Up & Cell lines & [69] \\
\hline H4K20 trimethylation & Down & Rodent models & [68] \\
\hline H3 global acetylation & Down and up & Cell lines & [70] \\
\hline H4 global acetylation & Down and up & Cell lines & [70] \\
\hline \multicolumn{4}{|l|}{ microRNA } \\
\hline miR-1 & Down & Cell lines, tumors & {$[73,77]$} \\
\hline miR-18 & Up & Tumors & {$[72,75,138]$} \\
\hline miR-21 & Up & Cell lines, tumors & {$[72-74,138]$} \\
\hline miR-122 & Down & Tumors & {$[73,77,81,138]$} \\
\hline miR-199 & Down & Tumors & {$[73-76,138]$} \\
\hline miR-221 & Up & Cell lines, tumors & {$[73,74,77,79,81,138]$} \\
\hline miR-222 & Up & Cell lines, tumors & {$[77,79]$} \\
\hline miR-224 & Up & Tumors & {$[75,78,138]$} \\
\hline
\end{tabular}

TSG, tumor suppressor gene.

\section{MicroRNAs and hepatocellular carcinoma}

MicroRNAs are a class of small non-coding RNAs (22 to 25 nucleotides) that repress gene expression by inhibiting the translation of messenger RNAs. MicroRNAs are considered to participate actively in HCC development, and this is supported by several studies in which significant changes in microRNA expression have been observed by comparing HCC tumors with non-cancerous tissues. For example, upregulation of microRNA-18 (miR-18), miR-21, miR-221, miR-222 and miR-224, and downregulation of miR-122, miR-125, miR-130a, miR-150, miR-199 and miR-200 and the let-7 family have been reported in HCC [72-78]. To understand the consequences of microRNA deregulation in hepatocarcinogenesis, several studies aimed to identify and validate target genes of these microRNAs. So far, microRNA alterations identified in liver tumors have mainly been associated with genes involved in cell cycle regulation and cell proliferation. For example, cyclin-dependent inhibitors p27 and p57 and Bcell lymphoma 2 (Bcl-2)-modifying factor are targets of miR-221/222, which are upregulated in HCC [79-81].
miR-1-1 is downregulated in HCC tumors compared with non-cancerous adjacent tissues, and its ectopic expression in HCC cell lines induced cell cycle inhibition and cell death [82]. Finally, miR-122 downregulation in HCC increases production of cyclin G1 [83], and overexpression of miR-22 in HCC cell lines results in increased cell proliferation and higher de novo tumor development in immune-compromised athymic or nude mice [84]. Taken together, these results are consistent with the critical role of microRNAs in the regulation of cell proliferation and apoptosis in hepatocytes, and highlight the importance of microRNA alterations in cellular transformation during hepatocarcinogenesis.

\section{Epigenetic alterations and HCC etiology}

Although the evidence for deregulation of epigenetic mechanisms during hepatocarcinogenesis has steadily accumulated over the past decade, their origins remain unclear. As many of these changes have been observed in early stages of carcinogenesis and even in precancerous stages $[63,85]$, it has been proposed that some of these 
alterations may be directly induced by exposure to specific risk factors, including $\mathrm{HBV}$ and $\mathrm{HCV}$ infection, alcohol intake and aflatoxin B1, and their presence may drive the process of hepatocarcinogenesis. For example, methylation in P16INK4A, GSPT1 and RASSF1A genes in HCC tumors has been significantly correlated with viral infection [86]. Comparison of methylation profiles between tumor samples associated with HBV infection, $\mathrm{HCV}$ infection and alcohol consumption has revealed a specific set of hypermethylated CpG islands for each group [87]. Our recent study also showed a significant association between the methylation pattern in HCC tumors and major risk factors, including HBV infection and alcohol intake [66]. Further studies are needed to test whether major risk factors induce a distinct set of early epigenetic events and whether these changes promote HCC development.

In addition to the well-established risk factors, nutrition deficiency could provide a favorable condition for HCC development. In a rat model of methyl-deficient or lipotrope-deficient diet-induced HCC, global hypomethylation has been found to be associated with tumor development [68]. Similarly, mouse models for alcoholic liver disease and non-alcoholic fat liver disease have provided evidence for microRNA deregulation in the diseased liver [88]. Furthermore, chronic alcohol consumption is also known to cause epigenetic alterations [89]: liver tissue from rats fed with alcohol presented a $40 \%$ loss of methylation, and chronic alcohol consumption caused global hypomethylation [90]. Finally, alcohol intake can also influence histone modifications, notably an increase in histone $\mathrm{H} 3$ acetylation [91]. In conclusion, viral infection or alcohol consumption seem to induce some specific epigenetic alterations, but the picture is far from being complete. Thus, the exact mechanism by which known risk factors trigger epigenetic changes and the precise gene targets remain to be elucidated.

\section{Cross-talk between epigenetic mechanisms and inflammatory pathways}

The link between inflammatory pathways and epigenetic mechanisms has been revealed by many recent studies using different model systems. There is growing evidence for a direct mechanistic relationship between the changes induced by inflammation and epigenetic deregulation during tumor development and progression [92,93]. We propose a working hypothesis that epigenome deregulation is an underlying mechanism by which inflammation may promote tumor development. In this scenario, different components of the inflammatory response may induce changes in epigenetic machinery or a so-called epigenetic switch that resets the long-term cellular memory system, a system that normally ensures the stable maintenance of transcriptional patterns and cell phenotype.

\section{Cross-talk between epigenetic mechanisms and} inflammatory pathways in HCC

As discussed earlier, inflammatory processes and epigenetic deregulation are early events in hepatocarcinogenesis. However, it remains unclear whether inflammation and a deregulated epigenome act concomitantly to initiate HCC or if there is a hierarchy and interdependence between them during cancer development and progression. Although cancer is traditionally considered a genetic disease caused by the accumulation of mutations, recent evidence suggests that epigenetic changes may play an important role in cancer development and could also act as precursor events that precede and promote genetic changes [94,95]. Here, we put forward the hypothesis that epigenetic deregulation may be an underlying mechanism by which inflammation promotes HCC development, as shown in Figure 1. In this scenario, different components of the inflammatory response may directly or indirectly induce changes in epigenetic machineries, including those involved in setting and propagating normal patterns of DNA methylation, histone modifications and non-coding RNAs in hepatocytes. Deregulated epigenetic states may contribute to a persistent inflammatory response through altered gene expression states and a positive feedback loop to exacerbate a chronic state of inflammation. In parallel, the deregulated epigenome maintains altered long-term memory systems that promote proliferation and oncogenic transformation (Figure 1). This interdependent and self-reinforcing cross-talk between inflammation and the epigenome maintains and amplifies inflammatory signals resulting in a series of events culminating in the development of liver cancer.

Several recent mechanistic and functional studies have provided support for our model by demonstrating interconnections between inflammatory pathways and epigenetic modifications. For example, chronic inflammation increases the level of ROS in the cytoplasm and high levels of ROS have been reported to induce the expression of SNAIL (the gene encoding a master regulator of the process of epithelial-mesenchymal transition), which can in turn recruit DNMTs (DNA-methyltransferases) and HDACs (histone deacetylases) to silence several specific genes $[63,96]$. In vivo alcohol intake or in vitro lipopolysaccharide treatment (an inflammatory stimulus) can induce $\mathrm{H} 3 \mathrm{~K} 9 / \mathrm{S} 10$ phosphorylation at the promoter of cytokine genes [97,98] and these specific histone marks appear to be required for NF- $\mathrm{kB}$ recruitment to the gene promoter [99]. Furthermore, it was shown that NF- $\kappa B$ interacts with HDAC-1 [100] and that the capacity of HDAC-1 to inactivate specific genes requires the presence of p50, an NF- $\mathrm{kB}$ subunit [101]. In contrast, epigenetic mechanisms can also interfere with inflammation pathways, notably in the activation of the JAK/STAT3 


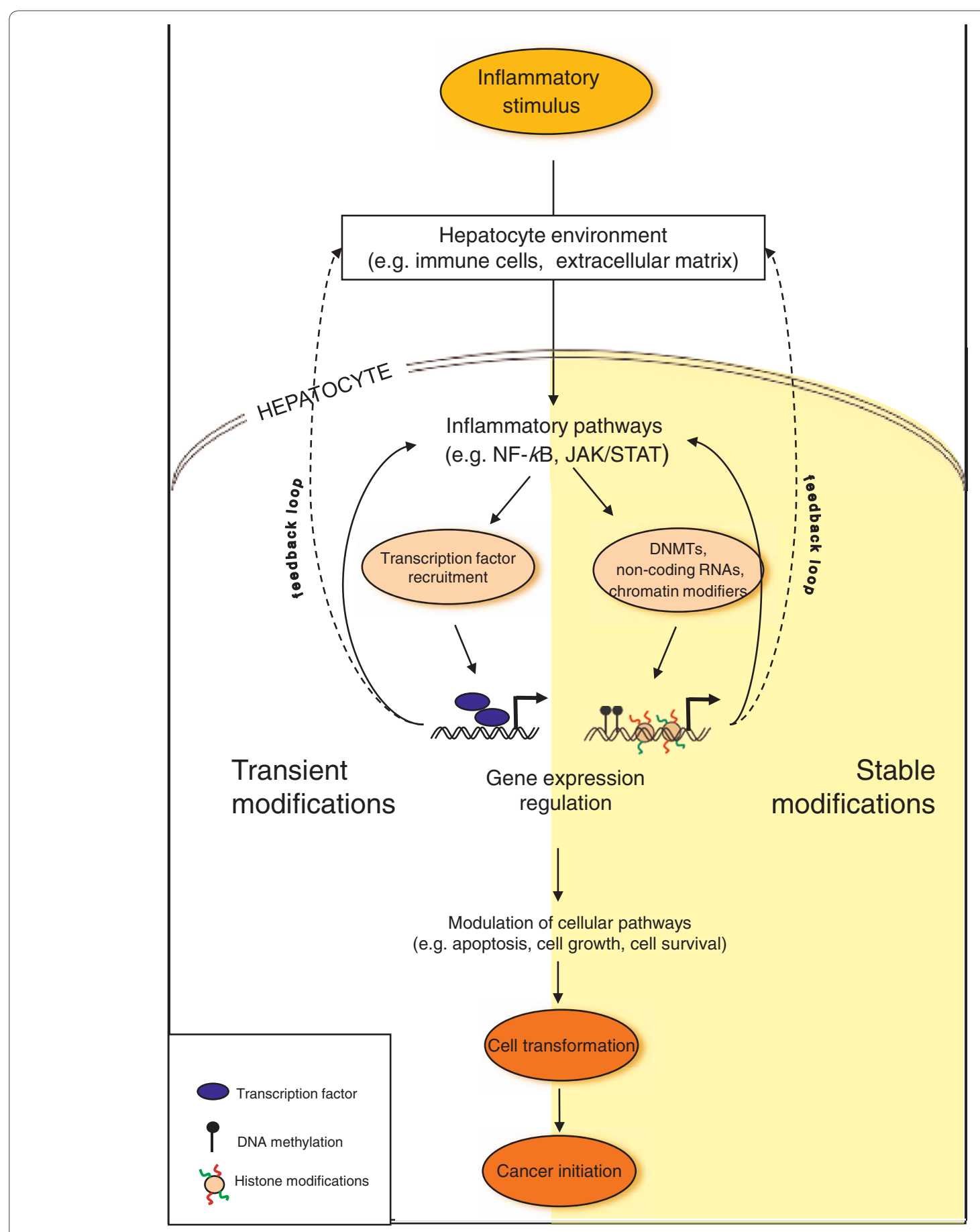

Figure 1. A hypothetical model depicting cross-talk between activation of inflammatory pathways and epigenome deregulation during liver tumor development. Different components of the inflammatory response (including transient and stable modifications such as activation of inflammatory pathways nuclear factor (NF)-KB and JAK/STAT) may induce changes in epigenetic machineries (including DNA methylation, histone modifications and non-coding RNAs), resulting in an 'epigenetic switch' that resets the long-term memory system in hepatocytes. The epigenetic switch in turn may contribute to a persistent inflammatory response through altered gene expression states and a positive feedback loop to exacerbate a chronic state of inflammation. In addition, the deregulated epigenome may maintain an altered transcriptional program that promotes proliferation and oncogenic transformation. This interdependent and self-reinforcing cross-talk between inflammation and the epigenome maintains and amplifies inflammatory signals, resulting in a series of events culminating in the development of liver cancer. The epigenetic switch may also be activated in hepatic or liver progenitor cells whose proliferation is stimulated during liver regeneration and repair. Therefore, an inflammatory microenvironment and an epigenetic switch in response to different environmental factors can directly promote activation of liver progenitor cells and their oncogenic transformation. DNMT, DNA methyl transferase. 
pathway. Analysis of HCC tumors revealed that aberrant silencing of JAK/STAT inhibitor genes SOCS-1 and SOCS-3 by DNA methylation results in constitutive activation of the pathway $[55,102]$. In addition, the binding of activated STAT3 to its target gene promoter seems to be dependent on histone acetylation status [71]. All these examples support the hypothesis that inflammation and epigenetic mechanisms are not separate but interdependent events whose cross-talk may deregulate a wide range of processes resulting in the development of HCC.

\section{Cross-talk between epigenetic mechanisms and} inflammatory pathways in liver stem/progenitor cells and liver cancer stem cells

Research on the process of liver cancer initiation has also focused on cells that might act as the precursors of liver cancer. The observation that HCC cells present specific markers that are common to stem cells and that progression of liver cancer is associated with dedifferentiation (a process by which a specialized, differentiated cell regresses to a simpler, more embryonic, unspecialized form) led to the 'maturation arrest hypothesis', which predicts that liver cancer may arise from stem cells that failed to complete their differentiation [103-107]. Hepatic or liver progenitor cells (LPCs) are adult stem cells that can differentiate into either hepatocytes or cholangiocytes $[108,109]$. Stem cells are activated when the replication of mature hepatocytes is blocked, in order to take over liver regeneration and repair [110-112]. Several studies have provided evidence to support the hypothesis of an LPC origin for liver cancer [109,113-115]. As exposure to different environmental factors can activate inflammation in liver cells, one current model proposes that the inflammatory microenvironment directly promotes LPC activation and transformation. More specifically, IL6, TNFo, IFNY and TWEAK (TNF-like weak inducer of apoptosis), a member of the TNF family, increased the numbers of rodent LPCs in vitro and in vivo [116-118]. Moreover, increasing proliferation of LPC by cytokines is not just a side-effect of inflammationinduced cell proliferation, since the proliferative effects of IFNY and TWEAK on LPCs have been shown to be specific to LPCs (when compared with hepatocytes).

Some cytokines and inflammatory pathways have even presented negative effects on LPC proliferation: for example, both IFN $\alpha$ and TGF $\beta$ reduce or block the proliferation of LPCs [119-121]. Deregulation of LPCs during carcinogenesis is likely to be associated with profound and heritable changes in cell fate programming. For these reasons, it has also been proposed that liver cancer may be initiated through the sustained epigenetic reprogramming of LPCs. The stemness/differentiation balance can be regulated by DNA methylation and bivalent marks (a combination of permissive and repressive histone marks) [95], and proteins responsible for the deposition of these marks are DNMTs and PcG proteins (Polycomb-group proteins), respectively. Therefore, inflammation may contribute to the transformation of LPCs by triggering epigenetic modifications. For example, cytokines such as IL6 or TGF $\beta$ have been shown to influence expression of DNMTs [122-124]. In addition, production of PcG proteins appears to be sensitive to cytokines: in the majority of human HCC samples, activation of JNK1 (a kinase that can be activated by cytokines) correlated with the increase of EZH2 PcG proteins [125]. In vitro studies of muscle stem cells confirmed the link between cytokines and PcG production by demonstrating that TNF $\alpha$ promotes the formation of Polycomb repressive complex [126]. In this manner, inflammation can directly affect LPC activation and differentiation by modifying the epigenetic memory system of these cells.

Finally, inflammation and epigenetic interactions can contribute to tumor development and progression by maintaining and expanding 'cancer stem cells' (CSCs). CSCs are defined as a discrete tumor population characterized by two defining properties: self-renewal and the capacity to reconstitute tumor heterogeneity [127]. Recent studies suggest a possible role for inflammation in the activation and maintenance of liver cancer stem cells. In a large series of HCC samples, the hepatic stem-cell-like subtype presented upregulation of the TGF $\beta$ pathway [128]. In healthy liver, LPCs have been found to produce OCT4, NANOG, STAT3 (the wellknown core stemness genes) and TBRII (TGF $\beta$-receptor type II), although subsequent analysis of cells producing STAT3/OCT4 markers of stemness failed to identify TBRII production [115]. This observation raises the possibility that disruption of the TGF $\beta$ pathway may promote the emergence of CSCs and sustain HCC development and progression $[129,130]$. One explanation could be that TGF $\beta$ disruption impairs differentiation of LPCs after their activation, thus promoting their transformation into liver cancer stem cells [131]. This hypothesis is further supported by a recent observation that TGF $\beta$ downregulation in liver cancer stem cells enhanced the mitogen-activated protein kinase (MAPK) pathway and thereby conferred resistance to apoptosis [132]. Similarly, other inflammatory pathways, such as the IL6/ JAK/STAT pathway, have been demonstrated to be capable of sustaining cancer stem cells. In a mouse model exhibiting disrupted TGF $\beta$ signaling, spontaneous liver cancer development and activation of IL6 signaling were observed [115], whereas in cell lines, the modulation of JAK/STAT was able to promote differentiation and elimination of CSCs [133]. Therefore, CSC activation is flexible and reversible, supporting the possibility that inflammatory 
pathways may impact on CSCs through epigenetic mechanisms. A report by You et al. [124] supports this hypothesis in the context of liver cancer by showing that TGF $\beta$ influences the expression of CD133 (a liver cancer stem cell marker) via aberrant DNA methylation at the CD133 promoter. In addition, it was shown that in breast cancer, microRNAs could directly influence CSC proliferation through modulation of the IL6/JAK/STAT pathway [134]. Taken together, accumulating evidence argues that inflammation may initiate the appearance and/or maintenance of cancer cells with stem cell features in liver and that epigenetic deregulation may be a key underlying mechanism.

Based on the evidence presented, we propose a model (Figure 1) in which various components of the inflammatory response (including activation of inflammatory pathways) induce changes in the epigenome (likely through deregulation of epigenetic machineries such as those mediating DNA methylation, histone modifications and non-coding RNAs). These changes represent an initiating event activating the 'epigenetic switch' that resets the long-term memory system in the target cells (hepatocytes). The epigenetic switch may be defined as stable and mitotically heritable changes in the epigenome that underlie transition in cell phenotype, and are maintained after the initial triggering events have ceased. This epigenetic switch may promote a persistent inflammatory state through both gene expression reprogramming and a feedback loop that amplifies inflammatory signals contributing to chronic inflammation. The deregulated epigenetic states may also maintain an altered transcriptional programme that promotes proliferation and oncogenic transformation. Thus, the self-reinforcing crosstalk between inflammation and the epigenome maintains and amplifies inflammatory signals, resulting in a series of events culminating in the development of HCC.

\section{Conclusions and further perspectives}

Abnormal secretions of cytokines are often observed in the presence of liver diseases and liver cancer. As a consequence, inflammatory pathways governing cell growth, cell cycle and cell survival are deregulated in hepatocytes. These pathways may enhance cytokine expression through positive feedback, thus creating a vicious circle that culminates in liver cancer. Evidence is accumulating to suggest that inflammation contributes to hepatocarcinogenesis through deregulation of the epigenome. Many studies have found a wide range of epigenetic alterations in HCC, consistent with the notion that aberrant DNA methylation, histone acetylation and expression of non-coding RNAs may be responsible for deregulated expression of numerous genes in transformed hepatocytes. Several lines of evidence suggest that inflammation and epigenetic deregulation are not independent events during hepatocarcinogenesis, but that they may cross-talk and cooperate directly or indirectly to induce cell transformation. In particular, studies on liver stem cells and their potential role in liver cancer strongly suggest that a cross-talk between inflammation and epigenetic mechanisms could be particularly relevant to the initiation of cancer stem cells and early stages of HCC development.

Epigenetic deregulation may provide the missing mechanistic link between inflammation and HCC development. Because the major treatment currently available for HBV and $\mathrm{HCV}$ infection is IFN $\alpha$ administration, which has relatively low efficacy $[15,135,136]$, a link between inflammation and epigenetic mechanisms suggests potential new targets for therapeutic intervention. Intrinsic reversibility of epigenetic changes and the recent development of drugs targeting epigenetic deregulation in cancer cells may provide an opportunity for targeting inflammation-epigenome cross-talk in liver cancer. A combination of classical antiviral agents (for example, INF administration) and epigenetic drugs (such as DNMT inhibitors or HDAC inhibitors) may prove particularly efficient for counteracting the synergy between cytokines and epigenome changes.

Despite important progress made in the field, several important questions remain to be addressed before we fully understand the functional impact of the interaction between inflammation and epigenome deregulation in liver tissue and define the precise underlying mechanisms. For example, to what extent is epigenetic deregulation triggered by chronic inflammation? Although activation of inflammatory pathways and disrupted epigenetic states commonly co-exist in liver cancer, hierarchies and the precise order of events that establish and maintain their cross-talk are far from being elucidated. Can inflammatory cytokines trigger epigenetic changes directly or indirectly? Does epigenetic deregulation contribute to chronic inflammation in the infected liver, and if so do positive feedback loops that amplify inflammatory responses exist? Another important question regards the origin of liver cancer stem cells and the role of inflammation and epigenetic mechanisms in their initiation and maintenance. The importance of epigenome reconfiguration in the maintenance of the defining features of stem/ progenitor cells provides a mechanistic explanation but also suggests potential targets for intervention. More comprehensive characterization of the epigenome of HCC tumors and liver cancer stem cells may help in answering some of these key questions.

\section{Abbreviations}

CSC, cancer stem cell; DNMT, DNA methyl transferase; HBV , hepatitis B virus; HCC, hepatocellular carcinoma; HCV, hepatitis C virus; HDAC, histone deacetylase; IFN, interferon; IL, interleukin; JAK, janus kinase; LPC, liver progenitor cell; NF, nuclear factor; $\mathrm{PCG}$, Polycomb group; ROS, reactive 
oxygen species; STAT, signal transducers and activators of transcription; TGF, transforming growth factor; TNF, tumor necrosis factor; TSG, tumor suppressor gene.

\section{Competing interests}

The authors declare that they have no competing interests.

\section{Acknowledgements}

We apologize to authors whose relevant publications were not cited due to space limitations. The work in the Epigenetics Group at the Internationa Agency for Research on Cancer (Lyon, France) is supported by grants from l'Agence Nationale de Recherche Contre le Sida et Hépatites Virales (ANRS, France), l'Association pour la Recherche sur le Cancer (ARC), France, and la Ligue Nationale (Française) Contre le Cancer, France (to ZH). The founders had no role in study design, data collection and analysis, decision to publish, or preparation of the manuscript.

Published: 31 January 2012

\section{References}

1. Llovet JM, Burroughs A, Bruix J: Hepatocellular carcinoma. Lancet 2003, 362:1907-1917.

2. Ferlay J, Shin HR, Bray F, Forman D, Mathers C, Parkin DM: Estimates of worldwide burden of cancer in 2008: GLOBOCAN 2008. Int J Cancer 2010, 127:2893-2917

3. Lata J: Chronic liver diseases as liver tumor precursors. Dig Dis 2010, 28:596-599.

4. Brait M, Sidransky D: Cancer epigenetics: above and beyond. Toxicol Mech Methods 2011, 21:275-288

5. Jones PA, Baylin SB: The fundamental role of epigenetic events in cancer. Nat Rev Genet 2002, 3:415-428.

6. Ballestar E, Esteller M: Epigenetic gene regulation in cancer. Adv Genet 2008, 61:247-267.

7. Rodriguez-Paredes M, Esteller M: Cancer epigenetics reaches mainstream oncology. Nat Med 2011, 17:330-339.

8. Pogribny IP: Epigenetic events in tumorigenesis: putting the pieces together. Exp Oncol 2010, 32:132-136

9. Nephew KP, Huang TH: Epigenetic gene silencing in cancer initiation and progression. Cancer Lett 2003, 190:125-133.

10. Lima SC, Hernandez-Vargas H, Herceg Z: Epigenetic signatures in cancer: Implications for the control of cancer in the clinic. Curr Opin Mol Ther 2010 12:316-324.

11. Herceg Z, Paliwal A: Epigenetic mechanisms in hepatocellular carcinoma: how environmental factors influence the epigenome. Mutat Res 2011, 727:55-61.

12. Luedde T, Trautwein C: Intracellular survival pathways in the liver. Liver Int 2006, 26:1163-1174

13. Tacke F, Luedde T, Trautwein C: Inflammatory pathways in liver homeostasis and liver injury. Clin Rev Allergy Immunol 2009, 36:4-12.

14. Berasain C, Castillo J, Perugorria MJ, Latasa MU, Prieto J, Avila MA: Inflammation and liver cancer: new molecular links. Ann N Y Acad Sci 2009, 1155:206-221

15. Gao B: Cytokines, STATs and liver disease. Cell Mol Immunol 2005, 2:92-100.

16. Bartsch H, Nair J: Chronic inflammation and oxidative stress in the genesis and perpetuation of cancer: role of lipid peroxidation, DNA damage, and repair. Langenbecks Arch Surg 2006, 391:499-510.

17. Grivennikov SI, Greten FR, Karin M: Immunity, inflammation, and cancer. Cell 2010, 140:883-899.

18. Bouchard MJ, Navas-Martin S: Hepatitis B and C virus hepatocarcinogenesis: lessons learned and future challenges. Cancer Lett 2011, 305:123-143.

19. Gurtsevitch VE: Human oncogenic viruses: hepatitis $B$ and hepatitis $C$ viruses and their role in hepatocarcinogenesis. Biochemistry (Mosc) 2008 73:504-513.

20. But DY, Lai CL, Yuen MF: Natural history of hepatitis-related hepatocellular carcinoma. World J Gastroenterol 2008, 14:1652-1656.

21. Bertoletti A, Maini MK, Ferrari C: The host-pathogen interaction during HBV infection: immunological controversies. Antiviral therapy 2010, 15(Suppl 3):15-24.

22. Brechot $C$, Kremsdorf $D$, Soussan $P$, Pineau P, Dejean $A$, Paterlini-Brechot $P$, Tiollais P: Hepatitis B virus (HBV)-related hepatocellular carcinoma (HCC) molecular mechanisms and novel paradigms. Pathologie-biologie 2010,
58:278-287.

23. Murakami Y, Saigo K, Takashima H, Minami M, Okanoue T, Brechot C, PaterliniBrechot P: Large scaled analysis of hepatitis $B$ virus (HBV) DNA integration in HBV related hepatocellular carcinomas. Gut 2005, 54:1162-1168.

24. Murakami Y, Minami M, Daimon Y, Okanoue T: Hepatitis B virus DNA in liver, serum, and peripheral blood mononuclear cells after the clearance of serum hepatitis B virus surface antigen. J Med Virol 2004, 72:203-214

25. Bouchard MJ, Schneider RJ: The enigmatic X gene of hepatitis B virus. J Virol 2004, 78:12725-12734.

26. Caselmann WH: Transactivation of cellular gene expression by hepatitis $B$ viral proteins: a possible molecular mechanism of hepatocarcinogenesis. J Hepatol 1995, 22:34-37.

27. Ray RB, Meyer K, Ray R: Suppression of apoptotic cell death by hepatitis C virus core protein. Virology 1996, 226:176-182.

28. Ray RB, Steele R, Meyer K, Ray R: Transcriptional repression of $\mathrm{p} 53$ promoter by hepatitis C virus core protein. J Biol Chem 1997, 272:10983-10986.

29. Holt AP, Salmon M, Buckley CD, Adams DH: Immune interactions in hepatic fibrosis. Clin Liver Dis 2008, 12:861-882, x

30. Viebahn CS, Yeoh GC: What fires prometheus? The link between inflammation and regeneration following chronic liver injury. Int I Biochem Cell Biol 2008, 40:855-873

31. Budhu A, Wang XW: The role of cytokines in hepatocellular carcinoma. J Leukoc Biol 2006, 80:1197-1213.

32. Hsia CY, Huo TI, Chiang SY, Lu MF, Sun CL, Wu JC, Lee PC, Chi CW, Lui WY, Lee SD: Evaluation of interleukin-6, interleukin-10 and human hepatocyte growth factor as tumor markers for hepatocellular carcinoma. Eur J Surg Oncol 2007, 33:208-212.

33. Nakazaki H: Preoperative and postoperative cytokines in patients with cancer. Cancer 1992, 70:709-713.

34. Hu RH, Lee PH, Yu SC: Secretion of acute-phase proteins before and after hepatocellular carcinoma resection. J Formos Med Assoc 1999, 98:85-91.

35. Beckebaum S, Zhang X, Chen X, Yu Z, Frilling A, Dworacki G, Grosse-Wilde H, Broelsch CE, Gerken G, Cicinnati VR: Increased levels of interleukin-10 in serum from patients with hepatocellular carcinoma correlate with profound numerical deficiencies and immature phenotype of circulating dendritic cell subsets. Clin Cancer Res 2004, 10:7260-7269.

36. Yuen MF, Norris S, Evans LW, Langley PG, Hughes RD: Transforming growth factor-beta 1, activin and follistatin in patients with hepatocellular carcinoma and patients with alcoholic cirrhosis. Scand J Gastroenterol 2002 37:233-238.

37. Kitaoka S, Shiota G, Kawasaki H: Serum levels of interleukin-10, interleukin-12 and soluble interleukin-2 receptor in chronic liver disease type C. Hepatogastroenterology 2003, 50:1569-1574.

38. Huang YS, Hwang SJ, Chan CY, Wu JC, Chao Y, Chang FY, Lee SD: Serum levels of cytokines in hepatitis C-related liver disease: a longitudinal study. Zhonghua Yi Xue Za Zhi (Taipei) 1999, 62:327-333.

39. Chia CS, Ban K, Ithnin H, Singh H, Krishnan R, Mokhtar S, Malihan N, Seow HF: Expression of interleukin-18, interferon-gamma and interleukin-10 in hepatocellular carcinoma. Immunol Lett 2002, 84:163-172.

40. Tangkijvanich P, Thong-Ngam D, Mahachai V, Theamboonlers A, Poovorawan $Y$ : Role of serum interleukin-18 as a prognostic factor in patients with hepatocellular carcinoma. World J Gastroentero/ 2007, 13:4345-4349.

41. Zekri AR, Ashour MS, Hassan A, Alam El-Din HM, El-Shehaby AM, Abu-Shady $M A$ : Cytokine profile in Egyptian hepatitis $C$ virus genotype- 4 in relation to liver disease progression. World J Gastroenterol 2005, 11:6624-6630.

42. Bortolami M, Venturi C, Giacomelli L, Scalerta R, Bacchetti S, Marino F, Florean A, Lise $M$, Naccarato $R$, Farinati F: Cytokine, infiltrating macrophage and T cell-mediated response to development of primary and secondary human liver cancer. Dig Liver Dis 2002, 34:794-801.

43. Song le $H$, Binh VQ, Duy DN, Kun JF, BockTC, Kremsner PG, Luty AJ: Serum cytokine profiles associated with clinical presentation in Vietnamese infected with hepatitis B virus. J Clin Virol 2003, 28:93-103.

44. Karin M: NF-kappaB as a critical link between inflammation and cancer. Cold Spring Harb Perspect Biol 2009, 1:a000141.

45. He G, Karin M: NF-kappaB and STAT3 - key players in liver inflammation and cancer. Cell Res 2011, 21:159-168.

46. Assenat E, Gerbal-chaloin S, Maurel P, Vilarem MJ, Pascussi JM: Is nuclear factor kappa-B the missing link between inflammation, cancer and alteration in hepatic drug metabolism in patients with cancer? Eur $J$ Cancer 2006, 42:785-792

47. Maeda S, Omata M: Inflammation and cancer: role of nuclear factor- 
kappaB activation. Cancer Sci 2008, 99:836-842.

48. Liu P, Kimmoun E, Legrand A, Sauvanet A, Degott C, Lardeux B, Bernuau D: Activation of NF-kappa B, AP-1 and STAT transcription factors is a frequent and early event in human hepatocellular carcinomas. J Hepatol 2002, 37:63-71.

49. He G, Yu GY, Temkin V, Ogata H, Kuntzen C, Sakurai T, Sieghart W, PeckRadosavljevic M, Leffert HL, Karin M: Hepatocyte IKKbeta/NF-kappaB inhibits tumor promotion and progression by preventing oxidative stressdriven STAT3 activation. Cancer Cell 2011, 17:286-297.

50. Luedde T, Beraza N, Kotsikoris V, van Loo G, Nenci A, De Vos R, Roskams T, Trautwein C, Pasparakis M: Deletion of NEMO/IKKgamma in liver parenchymal cells causes steatohepatitis and hepatocellular carcinoma. Cancer Cell 2007, 11:119-132.

51. Pikarsky E, Porat RM, Stein I, Abramovitch R, Amit S, Kasem S, Gutkovich-Pyest E, Urieli-Shoval S, Galun E, Ben-Neriah Y: NF-kappaB functions as a tumour promoter in inflammation-associated cancer. Nature 2004, 431:461-466.

52. Haybaeck J, Zeller N, Wolf MJ, Weber A, Wagner U, Kurrer MO, Bremer J, lezzi G, Graf R, Clavien PA, Thimme R, Blum H, Nedospasov SA, Zatloukal K, Ramzan M, Ciesek S, Pietschmann T, Marche PN, Karin M, Kopf M, Browning JL, Aguzzi A, Heikenwalder M: A lymphotoxin-driven pathway to hepatocellular carcinoma. Cancer Cell 2009, 16:295-308.

53. Heinrich PC, Behrmann I, Haan S, Hermanns HM, Muller-Newen G, Schaper F: Principles of interleukin (IL)-6-type cytokine signalling and its regulation. Biochem J 2003, 374:1-20.

54. Z Zhang CH, Xu GL, Jia WD, Li JS, Ma JL, Ren WH, Ge YS, Yu JH, Liu WB, Wang W: Activation of STAT3 signal pathway correlates with twist and e-cadherin expression in hepatocellular carcinoma and their clinical significance. J Surg Res 2010 [Epub ahead of print].

55. Calvisi DF, Ladu S, Gorden A, Farina M, Conner EA, Lee JS, Factor VM, Thorgeirsson SS: Ubiquitous activation of Ras and Jak/Stat pathways in human HCC. Gastroenterology 2006, 130:1117-1128.

56. Park EJ, Lee JH, Yu GY, He G, Ali SR, Holzer RG, Osterreicher CH, Takahashi H, Karin M: Dietary and genetic obesity promote liver inflammation and tumorigenesis by enhancing IL-6 and TNF expression. Cell 2010, 140:197-208.

57. Sinčić N, Herceg Z: DNA methylation and cancer: ghosts and angels above the genes. Curr Opin Oncol 2011, 23:69-76.

58. Vaissiere T, Sawan C, Herceg Z: Epigenetic interplay between histone modifications and DNA methylation in gene silencing. Mutat Res 2008, 659:40-48.

59. Huang J: Current progress in epigenetic research for hepatocarcinomagenesis. Sci China C Life Sci 2009, 52:31-42

60. Lin CH, Hsieh SY, Sheen IS, Lee WC, Chen TC, Shyu WC, Liaw YF: Genomewide hypomethylation in hepatocellular carcinogenesis. Cancer Res 2001, 61:4238-4243

61. Lee HS, Kim BH, Cho NY, Yoo EJ, Choi M, Shin SH, Jang JJ, Suh KS, Kim YS, Kang GH: Prognostic implications of and relationship between $\mathrm{CpG}$ island hypermethylation and repetitive DNA hypomethylation in hepatocellular carcinoma. Clin Cancer Res 2009, 15:812-820

62. Wong N, Lam WC, Lai PB, Pang E, Lau WY, Johnson PJ: Hypomethylation of chromosome 1 heterochromatin DNA correlates with q-arm copy gain in human hepatocellular carcinoma. Am J Pathol 2001, 159:465-471.

63. Hamilton JP: Epigenetic mechanisms involved in the pathogenesis of hepatobiliary malignancies. Epigenomics 2010, 2:233-243.

64. Zhao J, Wu G, Bu F, Lu B, Liang A, Cao L, Tong X, Lu X, Wu M, Guo Y: Epigenetic silence of ankyrin-repeat-containing, $\mathrm{SH} 3$-domain-containing, and proline-rich-region- containing protein 1 (ASPP1) and ASPP2 genes promotes tumor growth in hepatitis B virus-positive hepatocellular carcinoma. Hepatology 2010, 51:142-153.

65. Zhang C, Li H, Wang Y, Liu W, Zhang Q, Zhang T, Zhang X, Han B, Zhou G: Epigenetic inactivation of the tumor suppressor gene RIZ1 in hepatocellular carcinoma involves both DNA methylation and histone modifications. J Hepatol 2010, 53:889-895.

66. Lambert MP, Paliwal A, Vaissiere T, Chemin I, Zoulim F, Tommasino M, Hainaut P, Sylla B, Scoazec JY, Tost J, Herceg Z: Aberrant DNA methylation distinguishes hepatocellular carcinoma associated with $\mathrm{HBV}$ and HCV infection and alcohol intake. J Hepatol 2011, 54:705-715.

67. Feinberg AP, Tycko B: The history of cancer epigenetics. Nat Rev Cancer 2004, 4:143-153.

68. Pogribny IP, Ross SA, Tryndyak VP, Pogribna M, Poirier LA, Karpinets TV: Histone $\mathrm{H} 3$ lysine 9 and $\mathrm{H} 4$ lysine 20 trimethylation and the expression of
Suv4-20h2 and Suv-39h1 histone methyltransferases in hepatocarcinogenesis induced by methyl deficiency in rats. Carcinogenesis 2006, 27:1180-1186.

69. Yao JY, Zhang L, Zhang X, He ZY, Ma Y, Hui L, Wang X, Hu YP: H3K27 trimethylation is an early epigenetic event of p16INK4a silencing for regaining tumorigenesis in fusion reprogrammed hepatoma cells. J Biol Chem 2010, 285:18828-18837.

70. Park IY, Sohn BH, Yu E, Suh DJ, Chung YH, Lee JH, Surzycki SJ, Lee Yl: Aberrant epigenetic modifications in hepatocarcinogenesis induced by hepatitis $B$ virus X protein. Gastroenterology 2007, 132:1476-1494.

71. Won C, Lee CS, Lee JK, Kim TJ, Lee KH, Yang YM, Kim YN, Ye SK, Chung MH: CADPE suppresses cyclin D1 expression in hepatocellular carcinoma by blocking IL-6-induced STAT3 activation. Anticancer Res 2010, 30:481-488.

72. Ladeiro Y, Couchy G, Balabaud C, Bioulac-Sage P, Pelletier L, Rebouissou S, Zucman-Rossi J: MicroRNA profiling in hepatocellular tumors is associated with clinical features and oncogene/tumor suppressor gene mutations. Hepatology 2008, 47:1955-1963.

73. Jiang J, Gusev Y, Aderca I, Mettler TA, Nagorney DM, Brackett DJ, Roberts LR, Schmittgen TD: Association of MicroRNA expression in hepatocellular carcinomas with hepatitis infection, cirrhosis, and patient survival. Clin Cancer Res 2008, 14:419-427.

74. Gramantieri L, Fornari F, Callegari E, Sabbioni S, Lanza G, Croce CM, Bolondi L, Negrini M: MicroRNA involvement in hepatocellular carcinoma. J Cell Mol Med 2008, 12:2189-2204.

75. Huang YS, Dai Y, Yu XF, Bao SY, Yin YB, Tang M, Hu CX: Microarray analysis of microRNA expression in hepatocellular carcinoma and non-tumorous tissues without viral hepatitis. J Gastroenterol Hepatol 2008, 23:87-94.

76. Ji J, Wang XW: New kids on the block: diagnostic and prognostic microRNAs in hepatocellular carcinoma. Cancer Biol Ther 2009, 8:1686-1693.

77. Wong QW, Lung RW, Law PT, Lai PB, Chan KY, To KF, Wong N: MicroRNA-223 is commonly repressed in hepatocellular carcinoma and potentiates expression of Stathmin 1. Gastroenterology 2008, 135:257-269.

78. Wang Y, Lee AT, Ma JZ, Wang J, Ren J, Yang Y, Tantoso E, Li KB, Ooi LL, Tan P, Lee CG: Profiling microRNA expression in hepatocellular carcinoma reveals microRNA-224 up-regulation and apoptosis inhibitor-5 as a microRNA224-specific target. J Biol Chem 2008, 283:13205-13215.

79. le Sage C, Nagel R, Egan DA, Schrier M, Mesman E, Mangiola A, Anile C, Maira G, Mercatelli N, Ciafrè SA, Farace MG, Agami R: Regulation of the p27(Kip1) tumor suppressor by miR-221 and miR-222 promotes cancer cell proliferation. EMBO J 2007, 26:3699-3708.

80. Fornari F, Gramantieri L, Ferracin M, Veronese A, Sabbioni S, Calin GA, Grazi GL, Giovannini C, Croce CM, Bolondi L, Negrini M: MiR-221 controls CDKN1C/ p57 and CDKN1B/p27 expression in human hepatocellular carcinoma. Oncogene 2008, 27:5651-5661.

81. Gramantieri L, Fornari F, Ferracin M, Veronese A, Sabbioni S, Calin GA, Grazi GL, Croce CM, Bolondi L, Negrini M: MicroRNA-221 targets Bmf in hepatocellular carcinoma and correlates with tumor multifocality. Clin Cancer Res 2009, 15:5073-5081.

82. Datta J, Kutay H, Nasser MW, Nuovo GJ, Wang B, Majumder S, Liu CG, Volinia S, Croce CM, Schmittgen TD, Ghoshal K, Jacob ST: Methylation mediated silencing of MicroRNA-1 gene and its role in hepatocellular carcinogenesis. Cancer Res 2008, 68:5049-5058.

83. Gramantieri L, Ferracin M, Fornari F, Veronese A, Sabbioni S, Liu CG, Calin GA Giovannini C, Ferrazzi E, Grazi GL, Croce CM, Bolondi L, Negrini M: Cyclin G1 is a target of miR-122a, a microRNA frequently down-regulated in human hepatocellular carcinoma. Cancer Res 2007, 67:6092-6099.

84. Zhang J, Yang Y, Yang T, Liu Y, Li A, Fu S, Wu M, Pan Z, Zhou W: microRNA-22, downregulated in hepatocellular carcinoma and correlated with prognosis, suppresses cell proliferation and tumourigenicity. Br J Cancer 2010, 103:1215-1220

85. Feo F, Frau M, Tomasi ML, Brozzetti S, Pascale RM: Genetic and epigenetic control of molecular alterations in hepatocellular carcinoma. Exp Biol Med (Maywood) 2009, 234:726-736.

86. Katoh H, Shibata T, Kokubu A, Ojima H, Fukayama M, Kanai Y, Hirohashi S: Epigenetic instability and chromosomal instability in hepatocellular carcinoma. Am J Pathol 2006, 168:1375-1384

87. Hernandez-Vargas H, Lambert MP, Le Calvez-Kelm F, Gouysse G, McKayChopin S, Tavtigian SV, Scoazec JY, Herceg Z: Hepatocellular carcinoma displays distinct DNA methylation signatures with potential as clinical predictors. PLoS One 2010, 5:e9749.

88. Dolganiuc A, Petrasek J, Kodys K, Catalano D, Mandrekar P, Velayudham A, 
Szabo G: MicroRNA expression profile in Lieber-DeCarli diet-induced alcoholic and methionine choline deficient diet-induced nonalcoholic steatohepatitis models in mice. Alcohol Clin Exp Res 2009, 33:1704-1710.

89. Mandrekar P: Epigenetic regulation in alcoholic liver disease. World J Gastroenterol 2011, 17:2456-2464.

90. Lu SC, Martinez-Chantar ML, Mato JM: Methionine adenosyltransferase and $S$-adenosylmethionine in alcoholic liver disease. J Gastroenterol Hepatol 2006, 21(Suppl 3):S61-64

91. Park PH, Lim RW, Shukla SD: Involvement of histone acetyltransferase (HAT) in ethanol-induced acetylation of histone $\mathrm{H} 3$ in hepatocytes: potential mechanism for gene expression. Am J Physiol Gastrointest Liver Physiol 2005, 289:G1124-1136.

92. Niwa T, Ushijima T: Induction of epigenetic alterations by chronic inflammation and its significance on carcinogenesis. Adv Genet 2010, 71:41-56.

93. Niwa T, Tsukamoto T, Toyoda T, Mori A, Tanaka H, Maekita T, Ichinose M, Tatematsu M, Ushijima T: Inflammatory processes triggered by Helicobacter pylori infection cause aberrant DNA methylation in gastric epithelial cells. Cancer Res 2010, 70:1430-1440.

94. Feinberg AP, Ohlsson R, Henikoff S: The epigenetic progenitor origin of human cancer. Nat Rev Genet 2006, 7:21-33.

95. Hernandez-Vargas $\mathrm{H}$, Sincic N, Ouzounova M, Herceg Z: Epigenetic signatures in stem cells and cancer stem cells. Epigenomics 2009, 1:20.

96. Lim SO, Gu JM, Kim MS, Kim HS, Park YN, Park CK, Cho JW, Park YM, Jung G: Epigenetic changes induced by reactive oxygen species in hepatocellular carcinoma: methylation of the E-cadherin promoter. Gastroenterology 2008, 135:2128-2140, 2140 e2121-2128.

97. Yamamoto Y, Verma UN, Prajapati S, Kwak YT, Gaynor RB: Histone H3 phosphorylation by IKK-alpha is critical for cytokine-induced gene expression. Nature 2003, 423:655-659

98. Saccani S, Pantano S, Natoli G: p38-Dependent marking of inflammatory genes for increased NF-kappa B recruitment. Nat Immunol 2002, 3:69-75.

99. Anest V, Hanson JL, Cogswell PC, Steinbrecher KA, Strahl BD, Baldwin AS: A nucleosomal function for IkappaB kinase-alpha in NF-kappaBdependent gene expression. Nature 2003, 423:659-663.

100. Zhong H, May MJ, Jimi E, Ghosh S: The phosphorylation status of nuclear $\mathrm{NF}$-kappa B determines its association with CBP/p300 or HDAC-1. Mol Cell 2002, 9:625-636.

101. Elsharkawy AM, Oakley F, Lin F, Packham G, Mann DA, Mann J: The NFkappaB p50:p50:HDAC-1 repressor complex orchestrates transcriptional inhibition of multiple pro-inflammatory genes. J Hepatol 2010, 53:519-527.

102. Niwa Y, Kanda H, Shikauchi Y, Saiura A, Matsubara K, Kitagawa T, Yamamoto Kubo T, Yoshikawa H: Methylation silencing of SOCS-3 promotes cell growth and migration by enhancing JAK/STAT and FAK signalings in human hepatocellular carcinoma. Oncogene 2005, 24:6406-6417.

103. Alison MR, Islam S, Lim S: Stem cells in liver regeneration, fibrosis and cancer: the good, the bad and the ugly. J Pathol 2009, 217:282-298.

104. Wu PC, Fang JW, Lau VK, Lai CL, Lo CK, Lau JY: Classification of hepatocellular carcinoma according to hepatocellular and biliary differentiation markers. Clinical and biological implications. Am J Pathol 1996, 149:1167-1175.

105. Yoon DS, Jeong J, Park YN, Kim KS, Kwon SW, Chi HS, Park C, Kim BR: Expression of biliary antigen and its clinical significance in hepatocellular carcinoma. Yonsei Med J 1999, 40:472-477.

106. Uenishi T, Kubo S, Yamamoto T, Shuto T, Ogawa M, Tanaka H, Tanaka S, Kaneda K, Hirohashi K: Cytokeratin 19 expression in hepatocellular carcinoma predicts early postoperative recurrence. Cancer Sci 2003, 94:851-857.

107. Yamashita T, Forgues M, Wang W, Kim JW, Ye Q, Jia H, Budhu A, Zanetti KA, Chen Y, Qin LX, Tang ZY, Wang XW: EpCAM and alpha-fetoprotein expression defines novel prognostic subtypes of hepatocellular carcinoma. Cancer Res 2008, 68:1451-1461.

108. Alison MR, Lovell MJ: Liver cancer: the role of stem cells. Cell Prolif 2005 , 38:407-421

109. Libbrecht L: Hepatic progenitor cells in human liver tumor development. World J Gastroenterol 2006, 12:6261-6265.

110. Roskams T: Progenitor cell involvement in cirrhotic human liver diseases: from controversy to consensus. J Hepatol 2003, 39:431-434.

111. Yang S, Koteish A, Lin H, Huang J, Roskams T, Dawson V, Diehl AM: Oval cells compensate for damage and replicative senescence of mature hepatocytes in mice with fatty liver disease. Hepatology 2004, 39:403-411.

112. Roskams TA, Libbrecht L, Desmet VJ: Progenitor cells in diseased human liver. Semin Liver Dis 2003, 23:385-396.

113. Knight B, Tirnitz-Parker JE, Olynyk JK: C-kit inhibition by imatinib mesylate attenuates progenitor cell expansion and inhibits liver tumor formation in mice. Gastroenterology 2008, 135:969-979, 979 e961.

114. Zulehner G, Mikula M, Schneller D, van Zijl F, Huber H, Sieghart W, GraslKraupp B, Waldhor T, Peck-Radosavljevic M, Beug H, Mikulits W: Nuclear betacatenin induces an early liver progenitor phenotype in hepatocellular carcinoma and promotes tumor recurrence. Am J Pathol 2010, 176:472-481.

115. Tang Y, Kitisin K, Jogunoori W, Li C, Deng CX, Mueller SC, Ressom HW, Rashid A, He AR, Mendelson JS, Jessup JM, Shetty K, Zasloff M, Mishra B, Reddy EP, Johnson L, Mishra L: Progenitor/stem cells give rise to liver cancer due to aberrant TGF-beta and IL-6 signaling. Proc Natl Acad Sci U S A 2008, 105:2445-2450.

116. Knight B, Yeoh GC, Husk KL, Ly T, Abraham LJ, Yu C, Rhim JA, Fausto N: Impaired preneoplastic changes and liver tumor formation in tumor necrosis factor receptor type 1 knockout mice. J Exp Med 2000, 192:1809-1818.

117. Brooling JT, Campbell JS, Mitchell C, Yeoh GC, Fausto N: Differential regulation of rodent hepatocyte and oval cell proliferation by interferon gamma. Hepatology 2005, 41:906-915.

118. Yeoh GC, Ernst M, Rose-John S, Akhurst B, Payne C, Long S, Alexander W, Croker B, Grail D, Matthews VB: Opposing roles of gp130-mediated STAT-3 and ERK-1/2 signaling in liver progenitor cell migration and proliferation. Hepatology 2007, 45:486-494.

119. Nguyen LN, Furuya MH, Wolfraim LA, Nguyen AP, Holdren MS, Campbell JS, Knight B, Yeoh GC, Fausto N, Parks WT: Transforming growth factor-beta differentially regulates oval cell and hepatocyte proliferation. Hepatology 2007, 45:31-41.

120. Preisegger KH, Factor VM, Fuchsbichler A, Stumptner C, Denk H, Thorgeirsson SS: Atypical ductular proliferation and its inhibition by transforming growth factor beta1 in the 3,5-diethoxycarbonyl-1,4-dihydrocollidine mouse model for chronic alcoholic liver disease. Lab Invest 1999, 79:103-109.

121. Lim R, Knight B, Patel K, McHutchison JG, Yeoh GC, Olynyk JK: Antiproliferative effects of interferon alpha on hepatic progenitor cells in vitro and in vivo. Hepatology 2006, 43:1074-1083.

122. Braconi C, Huang N, Patel T: MicroRNA-dependent regulation of DNA methyltransferase- 1 and tumor suppressor gene expression by interleukin-6 in human malignant cholangiocytes. Hepatology 2010, 51:881-890.

123. Meng F, Wehbe-Janek $H$, Henson R, Smith H, Patel T: Epigenetic regulation of microRNA-370 by interleukin-6 in malignant human cholangiocytes. Oncogene 2008, 27:378-386.

124. You H, Ding W, Rountree CB: Epigenetic regulation of cancer stem cell marker CD133 by transforming growth factor-beta. Hepatology 2010, 51:1635-1644

125. Chang Q, Zhang Y, Beezhold KJ, Bhatia D, Zhao H, Chen J, Castranova V, Shi X Chen F: Sustained JNK1 activation is associated with altered histone $\mathrm{H3}$ methylations in human liver cancer. J Hepatol 2009, 50:323-333.

126. Palacios D, Mozzetta C, Consalvi S, Caretti G, Saccone V, Proserpio V, Marquez VE, Valente S, Mai A, Forcales SV, Sartorelli V, Puri PL:TNF/p38alpha/ polycomb signaling to Pax7 locus in satellite cells links inflammation to the epigenetic control of muscle regeneration. Cell Stem Cell 2010, 7:455-469.

127. Visvader JE, Lindeman GJ: Cancer stem cells in solid tumours: accumulating evidence and unresolved questions. Nat Rev Cancer 2008, 8:755-768.

128. Yamashita T, Ji J, Budhu A, Forgues M, Yang W, Wang HY, Jia H, Ye Q, Qin LX, Wauthier E, Reid LM, Minato H, Honda M, Kaneko S, Tang ZY, Wang XW: EpCAM-positive hepatocellular carcinoma cells are tumor-initiating cells with stem/progenitor cell features. Gastroenterology 2009, 136:1012-1024.

129. Amin R, Mishra L: Liver stem cells and tgf-Beta in hepatic carcinogenesis. Gastrointest Cancer Res 2008, 2:S27-30.

130. Kitisin K, Pishvaian MJ, Johnson LB, Mishra L: Liver stem cells and molecular signaling pathways in hepatocellular carcinoma. Gastrointest Cancer Res 2007, 1:S13-21

131. Mishra L, Banker T, Murray J, Byers S, Thenappan A, He AR, Shetty K, Johnson L, Reddy EP: Liver stem cells and hepatocellular carcinoma. Hepatology 2009, 49:318-329

132. Ding W, Mouzaki M, You H, Laird JC, Mato J, Lu SC, Rountree CB: CD133+ liver cancer stem cells from methionine adenosyl transferase $1 \mathrm{~A}$-deficient mice demonstrate resistance to transforming growth factor (TGF)-beta-induced 
apoptosis. Hepatology 2009, 49:1277-1286

133. Yamashita T, Honda M, Nio K, Nakamoto Y, Takamura H, Tani T, Zen Y, Kaneko $\mathrm{S}$ : Oncostatin $\mathrm{m}$ renders epithelial cell adhesion molecule-positive liver cancer stem cells sensitive to 5 -Fluorouracil by inducing hepatocytic differentiation. Cancer Res 2010, 70:4687-4697.

134. Iliopoulos D, Hirsch HA, Struhl K: An epigenetic switch involving NF-kappaB, Lin28, Let-7 MicroRNA, and IL6 links inflammation to cell transformation. Cell 2009, 139:693-706.

135. Deny P, Zoulim F: Hepatitis B virus: from diagnosis to treatment. Pathol Biol (Paris) 2010, 58:245-253.

136. Muller C: Chronic hepatitis B and C - current treatment and future therapeutic prospects. Wien Med Wochenschr 2006, 156:391-396.

137. Huang WX, Huang P, Link H, Hillert J: Cytokine analysis in multiple sclerosis by competitive RT - PCR: A decreased expression of IL-10 and an increased expression of TNF-alpha in chronic progression. Mult Scler 1999, 5:342-348.

138. Murakami Y, Yasuda T, Saigo K, Urashima T, Toyoda H, Okanoue T, Shimotohno $\mathrm{K}$ : Comprehensive analysis of microRNA expression patterns in

hepatocellular carcinoma and non-tumorous tissues. Oncogene 2006, 25:2537-2545

doi:10.1186/gm307

Cite this article as: Martin M, Herceg Z: From hepatitis to hepatocellular carcinoma: a proposed model for cross-talk between inflammation and epigenetic mechanisms. Genome Medicine 2012, 4:8. 